\title{
Multiple smooth muscle tumours in neurofibromatosis presenting with chronic gastrointestinal bleeding
}

\author{
J.G.C. Cox, ${ }^{1}$ C.M.S. Royston ${ }^{2}$ and D.R. Sutton ${ }^{3}$ \\ Department of ${ }^{1}$ Neurology, ${ }^{2}$ Surgery and ${ }^{3}$ Gastroenterology, Hull Royal Infirmary, Hull HU3 2JZ, UK.
}

\begin{abstract}
Summary: Gastrointestinal involvement in neurofibromatosis is well recognised. We present an unusual manifestation of gastro-intestinal neurofibromatosis - chronic gastrointestinal bleeding from extensive smooth muscle tumours.
\end{abstract}

\section{Introduction}

Although gastrointestinal involvement in neurofibromatosis is common, it is not often symptomatic. One of the least frequent gastrointestinal associations of neurofibromatosis is multiple smooth muscle tumours. We report such a case which also illustrates the need to search for cutaneous manifestations of neurofibromatosis in patients with chronic unexplained gastrointestinal blood loss.

\section{Case report}

A 20 year old labourer presented in 1974 with abdominal discomfort and symptoms of anaemia. He had been taking aspirin for headaches for two weeks but had not noticed any change in bowel habit. His haemoglobin was $5.5 \mathrm{~g} / \mathrm{dl}$ with an MCV of $70 \mathrm{fl}$. He was a life-long non-smoker and nondrinker and there was no relevant past or family history. Examination revealed that he had melaena and he required blood transfusion. A barium meal, sigmoidoscopy and barium enema were all normal. Over the next 12 months his haemoglobin remained stable and a provisional diagnosis of bleeding secondary to aspirin ingestion was made.

In 1980 he had a further melaena, again having taken aspirin for several days previously. His haemoglobin was $6.4 \mathrm{~g} / \mathrm{dl}$ and he was transfused and given a total dose iron infusion. A barium meal was normal. A year later his iron deficiency anaemia recurred this time without aspirin ingestion or melaena.

Correspondence: J.G.C. Cox, M.A., M.R.C.P., Department of Neurology, Hull Royal Infirmary, Anlaby Road, Hull HU3 2JZ, UK.

Accepted: 12 August 1987
Gastroscopy, duodenal biopsies and flexible sigmoidoscopy were normal. A small bowel enema was reported as showing very extensive Crohn's disease with mucosal irregularity and stricturing involving the distal jejunum and most of the ileum. He remained remarkably well apart from mild abdominal discomfort for the next four years when he again presented with a melaena. His haemoglobin was $5.5 \mathrm{~g} / \mathrm{dl}$ and he required transfusion. Gastroscopy and serum orosomucoids were normal. A double contrast barium enema was normal and a repeat small bowel enema showed further extensive changes of Crohn's disease especially of the jejunum. Soft nodules were noted on his trunk and biopsy of one of these revealed a neurofibroma. $\mathrm{He}$ was treated with corticosteroids. Over the next six months he had a persistent slow gastro-intestinal blood loss, requiring 26 units of blood and two total dose iron infusions.

In December 1985 he returned with a severe melaena, and his haemoglobin was $4.3 \mathrm{~g} / \mathrm{dl}$. Shortly after admission a tin colloid radionucleide study and a superior mesenteric angiogram were normal. He was discharged from hospital well only to be readmitted later in the month with a further melaena. On this occasion a superior mesenteric angiogram showed active bleeding probably from the jejunum, but the precise site remained uncertain. He settled down on blood transfusions but a few days later developed abdominal pain, vomiting and signs of a perforated viscus.

At laparotomy he was found to have extensive involvement of the small bowel with multiple tumours (Figure 1), extending from $15 \mathrm{~cm}$ distal to the duodeno-jejunal flexure to $5 \mathrm{~cm}$ from the ileocaecal valve and one of these had perforated. There was no evidence of Crohn's disease. Sixty centi-

(C) The Fellowship of Postgraduate Medicine, 1988 


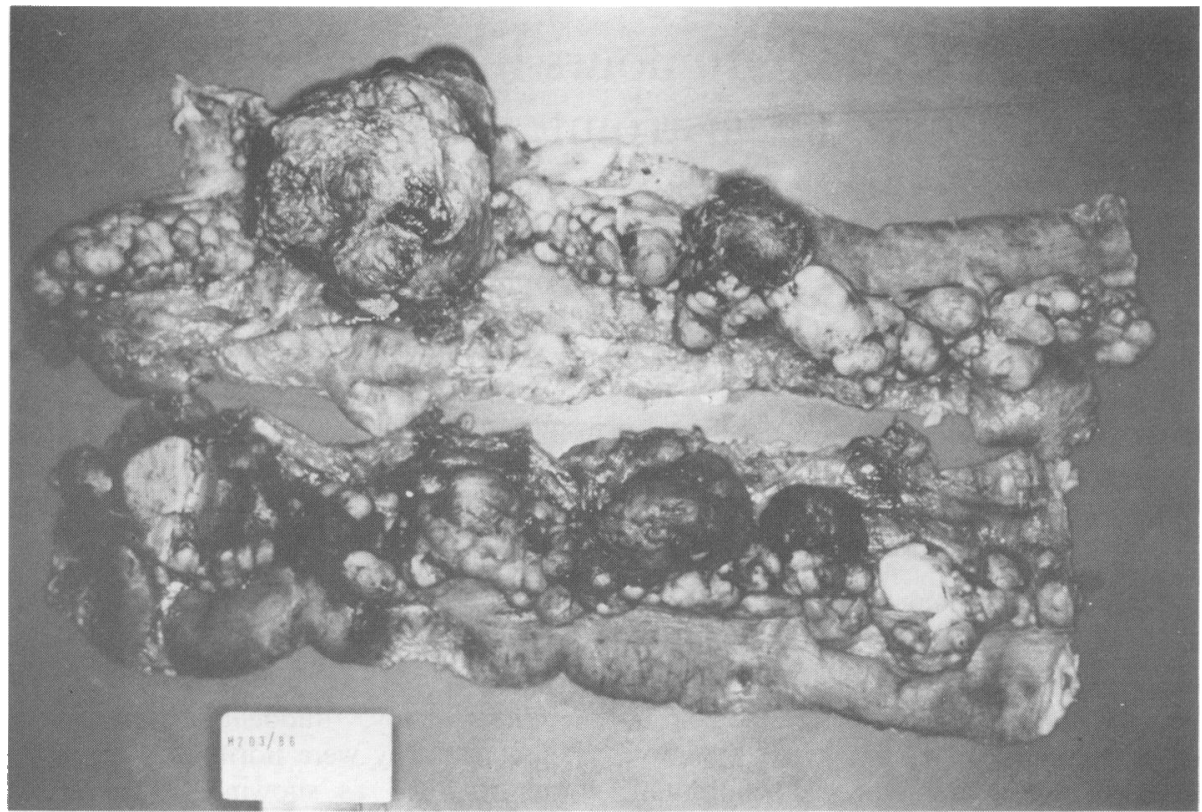

Figure 1 Multiple jejunal tumours (serosal surface).

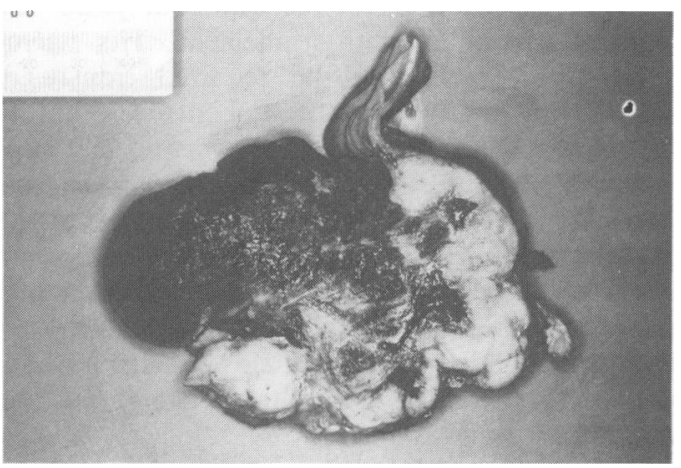

Figure 2 Infarcted jejunal tumour.

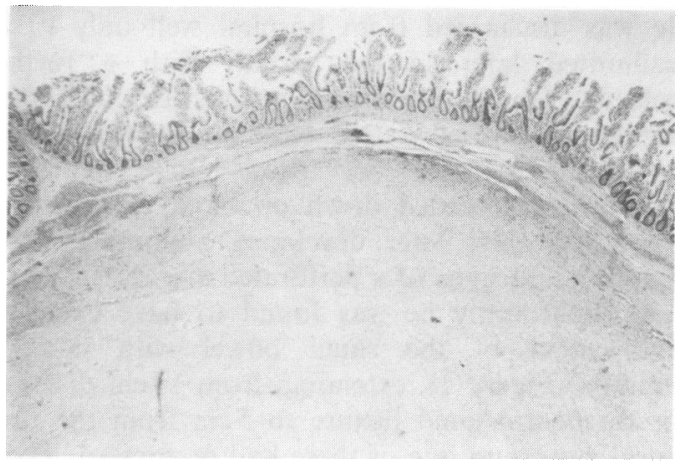

Figure 3 Smooth muscle tumour $(H \& E \times 4)$.

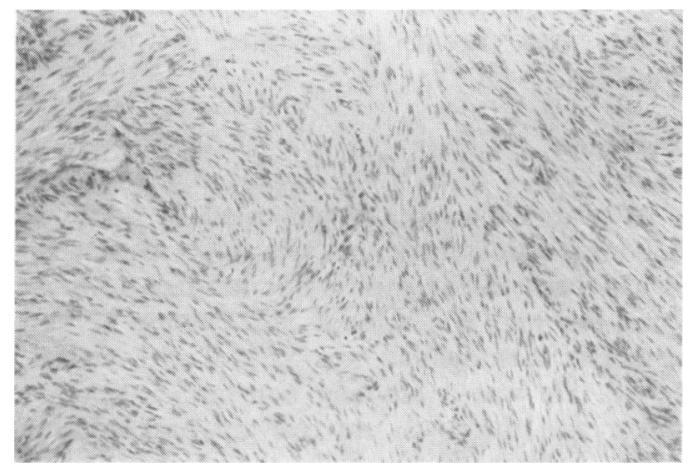

Figure 4 Smooth muscle tumour $(H \& E \times 10)$.

metres of jejunum was resected and following this he had an unremarkable post-operative course.

Examination of the resected jejunum revealed that the site of perforation was through an infarcted jejunal tumour (Figure 2). Histology revealed multiple intramural and submucosal smooth muscle tumours (Figures 3,4). There was no evidence of malignancy.

Nine months after surgery he remained extremely well and maintained a haemoglobin $13.3 \mathrm{~g} / \mathrm{dl}$ off iron.

\section{Discussion}

The frequency of involvement of the gastro- 
intestinal tract in neurofibromatosis varies from 12 $25 \%,{ }^{1,2}$ but only a small number of patients have symptoms. The jejunum and stomach are the most frequent sites $^{3}$ and the lesions are usually neurofibromas. Smooth muscle tumours, previously called leiomyomas and histologically indistinguishable from neurilemmomas ${ }^{4,5}$ are one of the commoner small bowel neoplasms but are very rare in neurofibromatosis. Up to 1986 only 14 cases of smooth muscle tumours of the small bowel in patients with neurofibromatosis had been reported in English language publications. ${ }^{3,6-12}$ That they occur in what was formerly thought to be neurectodermal dysplasia may be explained by the current concept of neurofibromatosis as a generalised hamartomatous dysplasia. ${ }^{5}$

Symptoms caused by small bowel tumours depend on the position in the gastrointestinal wall submucosal and intramuscular lesions can ulcerate, intussuscept, obstruct or perforate while subserosal lesions may cause no symptoms. Small bowel

\section{References}

1. Wonder, J.V. Neurofibromatosis. Curr Probl Surg 1977, 14: 1-81.

2. Davis, G.B. \& Berk, R.N. Intestinal neurofibromas in von Recklinghausen's disease. Am J Gastroenterol 1973, 60: $410-415$.

3. Hochberg, D.H., Da Silva, A.B., Galdabini, J. \& Richardson, E.P. Gastrointestinal involvement in von Recklinghausen's neurofibromatosis. Neurology 1974, 24: 1144-1151.

4. Morson, B.C. \& Dawson, I.M.P. Gastrointestinal Pathology. Blackwell, Oxford, 1979, p 192.

5. Morson, B.C. \& Dawson, I.M.P. Gastrointestinal Pathology. Blackwell, Oxford, 1979, pp 423-426.

6. Schaldenbrand, J.D. \& Appelman, H.D. Solitary solid stromal gastrointestinal tumours in von Recklinghausen's disease with minimal smooth muscle differentiation. Hum Pathol 1984, 15: 229-232.

7. Campbell, R.E. \& Young, J.M. Leiomyoma of duodenum. Am J Surg 1954, 88: 618.

8. River, L., Silverstein, J. \& Tope J.W. Benign neoplasms of the small intestine, a critical comprehensive review with reports of 20 new cases. Int Abst Surg 1956, 102 (1): 1-38. tumours in patients with neurofibromatosis may also present with occult or torrential gastrointestinal bleeding. ${ }^{10}$ Bell has described a patient with a retroperitoneal neurofibrosarcoma which caused chronic intermittent blood loss over 21 years by invasion of the bowel. ${ }^{13}$

This patient had a 15 year history of chronic gastro-intestinal blood loss. There was no family history of neurofibromatosis and the diagnosis of neurofibromatosis was made only late in his clinical course. Chronic unexplained gastro-intestinal blood loss should prompt a search for cutaneous signs of neurofibromatosis.

\section{Acknowledgements}

We would like to thank Dr D.M. Piercy, Department of Histopathology, Castle Hill Hospital, Cottingham, North Humberside, for his valuable contribution in the preparation of this manuscript. We would like to thank Mrs Peggy Milner for typing this manuscript.

9. Lukash, W.M., Morgan, R.I., Sennett, C.O. \& Nielson, O.F. Gastrointestinal neoplasms in von Recklinghausen's disease. Arch Surg 1966, 92: 905908.

10. Devereux, R.B., Koblenz, L.W., Cipriano, P. \& Gray, G.F. Gastro-intestinal haemorrhage - an unusual manifestation of neurofibromatosis. Am J Med 1975, 58: 135-138.

11. Perea, V.B. \& Gregory, L.J. Neurofibromatosis of the stomach. Report of a case associated with von Recklinghausen's disease and review of the literature. JAMA 1962, 182: 259-263.

12. Tong, H.K., Ann, T.K., Meng, G.H., Kok, L.S. \& Cheong, F.W. A case of primary duodenal carcinoma and small bowel leiomyomas in a patient with neurofibromatosis. Singapore Med J 1980, 21: 713716.

13. Bell, J.M., Ritch, A.E.S. \& Donovan, I.A. Neurofibrosarcoma in Von Recklinghausen's disease presenting with hypochromic anaemia. Postgrad Med $J$ 1983, 59: 38-39. 